\title{
The social development model of immigrants to Mars based on differential equation
}

\author{
Zhaoyu Wang ${ }^{1, a}$, Dong Tan ${ }^{2, b}$ \\ ${ }^{1}$ Ningbo University Science College,Zhejiang Ningbo 315000; 2 Ningbo University Business \\ College,Zhejiang Ningbo 315000
}

Keywords:social development model, logistic model,differential equation

\begin{abstract}
In this passage, we set up a mathematical model to solve the problem of moving a group of people to Mars and analyzed its fitness in different condition. First we set three basic priority factors: income, education and equality. To construct a successful society, we have to fulfill high income, high education standard and good equality. Also, we discussed population growth model and used logistic model to depict population growth. Second, we designed social development model based on three factors. We abstracted the society into three functional sectors: agriculture, manufactory and education, and we then set differential equations to analyze the growth of the society. After that, we set an objective function to cover all goals that we set above and get when the ratio is 0.31: 0.28: 0.41, we reaches its maximumdevelopment.
\end{abstract}

\section{Introduction}

With the aim of designing an economic-workforce-education system on Mars in the project UTOPIA:2100, specific immigration policy is crucial.The first wave of migration, called Population Zero, will include 10,000 people.Population Zero aims at creating a sustainable society with the maximum of both economic output(GDP) and happiness for its citizens. Laboratory of Interstellar Financial \& Exploration Policy (LIFE) has asked us to set up a policy model and create a sustainable life-plan. The model and plan proposed within this paper will offer an answer to these problems.

\section{General Assumption}

As our model will progress from simple to complex, some assumptions are required for different periods. However, some basic underlying assumptions run through this article.

- Assume that all people behave in accordance with the rational person hypothesis;

- Assume that all utility is in line with the law of diminishing marginal return law;

- Assume the minimum period of apply policies is one year. 


\section{Symbol Description}

Definitions of symbols employed in this paper are listed in the Table 1.

Table 1: Definitions of symbols

\begin{tabular}{|c|c|}
\hline Symbol & Description \\
\hline$g$ & The fertility \\
\hline$r$ & The intrinsic grow rate of population \\
\hline$F_{a g r}$ & The production distribution of agriculture \\
\hline$F_{\text {manu }}$ & The production distribution of manufacture \\
\hline$x(t)$ & The population at the time $t$ \\
\hline$x(0)$ & The population at the time $t_{0}$ \\
\hline$x_{m}$ & The maximum number of people \\
\hline ifli & The education (technology) multiplier \\
\hline
\end{tabular}

\section{Problem Formation}

When emigrate to the Mars, the first problem need to focus on is staying alive and agriculture, manufacture and education are the basic industries. The production distribution is as shown in Figure 1. To solve the problem, some assumptions about the production function of agriculture $F_{\text {agr }}$ and manufacture $F_{\text {manи }}$ must be applied:

1. The marginal product of each input is positive and decreasing.

2. Constant returns to scale.

3. Production function satisfies the paddy condition.

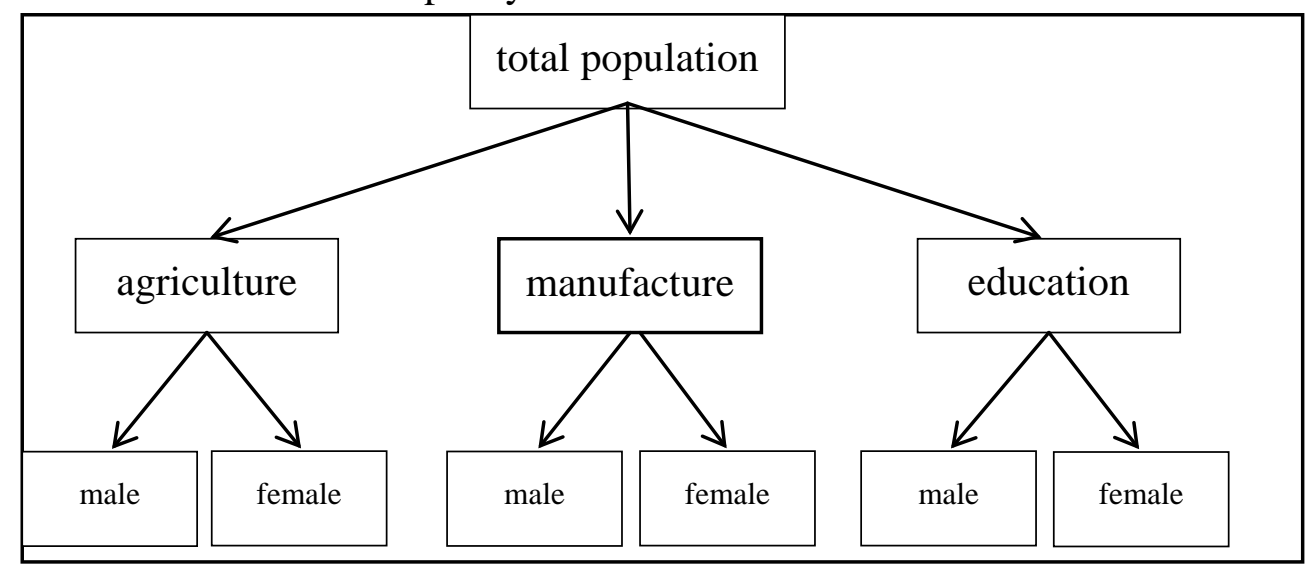

Figure 1: Production distribution chart on Mars

In our model, we set up three goals: the growth of income, the growth of education and the maintaining of social equality. Basically, we interested in the goal of the growth of income, because it could represent the overall growth of a society. And other two factors could affect the growth of income: the higher the education quality is, the faster the income growth would be. And social equality could affect the whole society's happiness, which will affect the growth of income. So, ideally we would like to keep this society in such condition: guaranteeing of rather high social happiness, we want to maximize the growth of social income and the growth of education. 


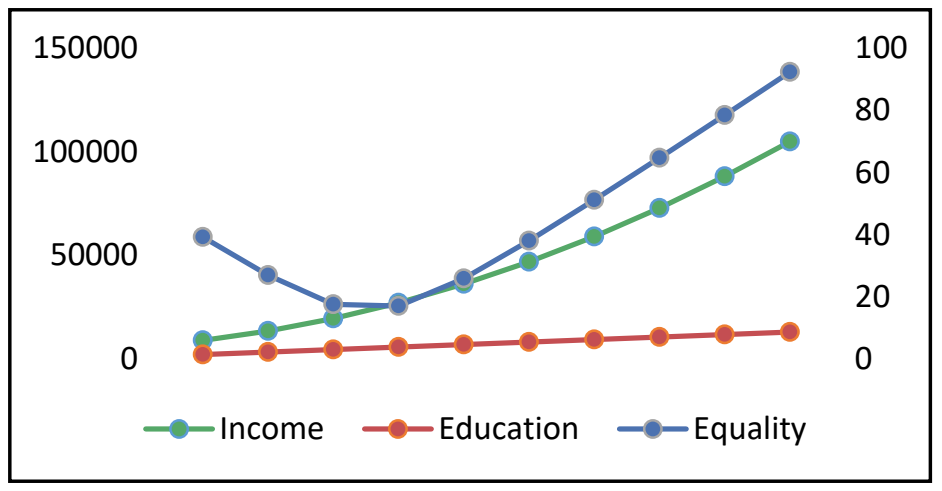

Figure 2: 10-year tendency of three goals

Figure 2 shows the tendency of three goals of our society in the beginning 10 years. We could observe that the growth of education is rather stable, while social income increases more rapidly. And the indicator we used to indicate social equality fluctuate more frequently and is subjected to various factors.

As for features of population that would contribute to the outcomes, we mainly consider the population volume, demographical indexes and individual working conditions. Population volume has a positive effect on society growth, while reversely it is restricted by food output. The larger the population is, the more food the whole society needs. And only when the net food output is positive, can we witness a society's population growth.

As for working conditions, we mainly interest the distribution of population in three departments agriculture, industry and education. Different distribution could lead to a different growth on society.

In order to get the future population size, we bring logistic model for the population:

Givenresources is limited on Mars, population will not grow exponentially. In order to get more accurate prediction results, we suppose that the rate of population growth varies with the number of population. Let $x(t)$ means the population at time $t, x(0)$ is the population at time $t_{0}$ and $r$ is the intrinsicgrowthrate of population. We take $r(t)=r-s x(t)$, in which $r, s>0$.

For the sake ofdetermining the significance of the coefficient $s$, we consider the maximum number of people $x_{m}$ that can be accommodated by natural resources and environmental conditions. When $x=x m, \quad r(m)=0$ and $s=r / x m$, then

$$
r(x)=r\left(1-x(t) / x_{m}\right) x(t)
$$

Finally, we can get a differential equation as follow:

$$
\left\{\begin{array}{l}
\frac{d x}{d t}=r\left(1-\frac{x(t)}{x_{m}}\right) x(t) \\
x(0)=x_{0}
\end{array}\right.
$$

The solution is

$$
x(t)=\frac{x_{m}}{1+\left(\frac{X_{m}}{X_{0}}-1\right) e^{-n}}
$$


Using the method above, we can figure out the population in the next ten years, under the assumption that each one of the first 10,000 people to emigrate to Mars is between the ages of 20 and 30. The results of our model in the next ten years are shown in Figure 3.

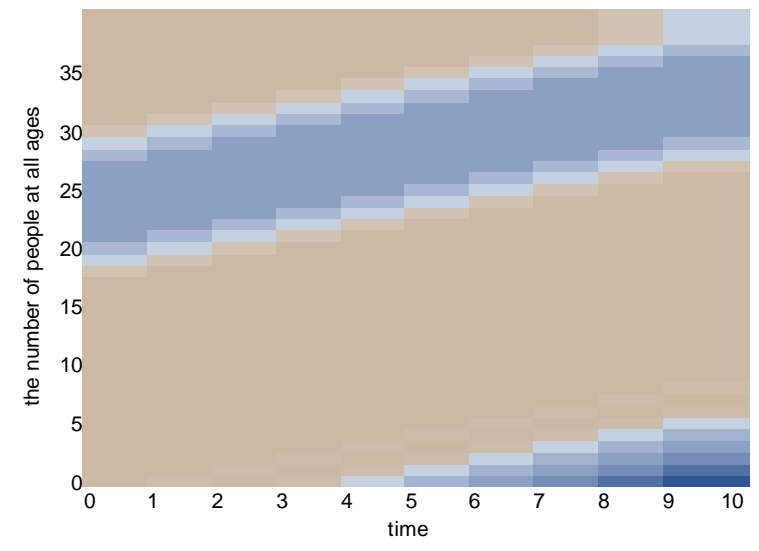

Figure 3: the head map of the distribution of people at all ages

In Figure 3, we can see: Although in the first 10 years, the population is unevenly distributed, but the population distribution is close to balance and the number of newborns is increasing consistently.

We mainly focused on parameters that could indicate the society's growth such as agriculture output, industrial output, education growth and population growth. As for the three factors-income, education and equality-these parameters affect them in different ways. For income, it is determined by the agriculture output and industrial output. For education, it is determined by education growth and population. And as for equality, which can also be viewed as happiness is determined by society's income and social wealth distribution.

Hence, using the basic rules and parameters we set above, we will be able to determine the quantitative relationship in this problem. First, we suppose there are $F_{l}$ female labors and $M_{l}$ male labors. And in different departments female and male laborhave different efficiency, $M R_{A}$, $F R_{A}, M R_{M}, F R_{M}, M R_{E}, F R_{E}$ respectively represent male labor and female labor efficiency in three departments (agriculture, manufactory and education). And we uselabor 1 , labor 2 , labor 3 to represent the labor distribution of labor in three departments. Also we know, the education level could boost the agriculture and manufactory production. So, we set up the multipliers agre and manue for them. Secondly, we define the input to agriculture, manufactory and education of agriculture products respectively as $\operatorname{Agrin}_{1}, \operatorname{Agrin}_{2}, \operatorname{Agrin}_{3}$ and define the input of industrial products

to three departments as Manuin $_{1}$, Manuin $_{2}$, Manuin $_{3}$. As is shown in Table 2 below:

Table 2: notations of variables

\begin{tabular}{cccc}
\hline Department & Agriculture & Manufactory & Education \\
\hline Male labor & $M_{l} \cdot$ labor $_{1}$ & $M_{l} \cdot$ labor $_{2}$ & M $_{l} \cdot$ labor $_{3}$ \\
Female labor & $F_{l} \cdot$ labor $_{1}$ & $F_{l} \cdot$ labor $_{2}$ & $F_{l} \cdot$ labor $_{3}$ \\
Male efficiency & MRA $_{A}$ & $M_{M}$ & $M_{E}$ \\
Female efficiency & $F_{A}$ & $F R_{M}$ & $F R_{E}$ \\
Agriculture products input & Agrin $_{1}$ & Agrin $_{2}$ & Agrin $_{3}$ \\
Manufactory products input & Manuin $_{1}$ & Manuin $_{2}$ & Manuin $_{3}$ \\
\hline
\end{tabular}


Therefore, the average wage of three departments would be:

$$
\begin{aligned}
& \text { Agriculture: } \text { Wage }_{1}=\frac{\text { Agrin }_{1}+\text { Manuin }_{1}}{\text { Iabor }_{1} \cdot \text { Pop }} \\
& \text { Manufactory: } \text { Wage }_{2}=\frac{\text { Agrin }_{2}+\text { Manuin }_{2}}{\text { labor }_{2} \cdot \text { Pop }} \\
& \text { Education: } \text { Wage }_{3}=\frac{\text { Agrin }_{3}+\text { Manuin }_{3}}{\text { labor }_{3} \cdot \text { Pop }}
\end{aligned}
$$

in which Pop means the population. Because education could not be considered as physical investments, we did not take education into consideration in this part specially.

Then, we could define the annually growth of three departments according to the analysis above:

$$
\begin{aligned}
& \Delta a g r=\left(M_{l} \cdot \text { labor }_{1} \cdot M R_{A}+F_{l} \cdot \text { labor }_{1} \cdot F R_{A}\right) \cdot\left(1+\frac{\text { Agrin }_{1}+\text { Manuin }_{1}}{100}\right) \cdot(1+\text { Edu } \cdot \text { agre })-\left(\text { Agrin }_{1}+\text { Agrin }_{2}+\text { Agrin }_{3}\right) \\
& \Delta \text { manu }=\left(M_{1} \cdot \text { labor }_{2} \cdot M_{M}+F_{1} \cdot \text { labor }_{2} \cdot F R_{M}\right) \cdot\left(1+\frac{\text { Agrin }_{2}+\text { Manuin }_{2}}{100}\right) \cdot\left(1+\text { Edu } \cdot \text { manue }-\left(\text { Manuin }_{1}+\text { Manuin }_{2}+\text { Manuin }_{3}\right)\right. \\
& \Delta e d u=\left(M_{l} \cdot \text { labor }_{3} \cdot M R_{E}+F_{l} \cdot \text { labor }_{3} \cdot F R_{E}\right) \cdot\left(1+\frac{\text { Agrin }_{3}+\text { Manuin }_{3}}{100}\right)
\end{aligned}
$$

Hence, the GDP or social income could be defined as:

$$
G D P=a g r+m a n u+e d u
$$

Social development optimization model. As we stated above, there are three main goals of our Population Zero, which are income growth, education growth and equality. Also, we have set up a series of parameters to indicate and release quantitative relationship among them. And we know that the income is mainly determined by physical output (food and manufactory products), science growth is determined by education growth and the social equality is determined by distribution of income. Combined with rules above and parameters I set above, we here set up a more comprehensive model.

First for agriculture, manufactory and education production, there are mainly 4 factors that affect their fluctuating: 1) Own volume. easily proved, the larger one department's volume is, the fiercer it will change; 2) The input self-balance. As all departments have a tendency to stay in a balance, if one department has a rather huge input in last period, it tends to have a relative less fierce fluctuating; 3) The boost of technology (education) improvement; 4) The environment restriction. A society's growth is subjected to its environment's ability and resources.

Hence, the rules above could be described as follow:

$$
\begin{aligned}
& \operatorname{dagr}=\left(M_{l}+F_{l}\right) \cdot\left(\text { labor }_{1} \cdot M R_{E}-\operatorname{Cost}_{A}\right) \cdot a g r \cdot\left(1-\frac{a g r}{a g r+m a n u+e d u}\right) \cdot\left(1+i f l_{1} \cdot \frac{e d u}{a g r+m a n u+e d u}\right) \cdot\left(1-\frac{a g r+m a n u+e d u}{G D P M}\right) \\
& d \text { manu }=\left(M_{l}+F_{l}\right) \cdot\left(\text { labor }_{2} \cdot M R_{M}-\operatorname{Cost}_{B}\right) \cdot m a n u \cdot\left(1-\frac{m a n u}{a g r+m a n u+e d u}\right) \cdot\left(1+i f l_{2} \cdot \frac{e d u}{a g r+m a n u+e d u}\right) \cdot\left(1-\frac{a g r+m a n u+e d u}{G D P M}\right) \\
& \operatorname{dedu}=\left(M_{l}+F_{l}\right) \cdot\left(\text { labor }_{3} \cdot M R_{E}\right) \cdot e d u \cdot\left(1-\frac{e d u}{a g r+m a n u+e d u}\right) \cdot\left(1+i f l_{3} \cdot \frac{e d u}{a g r+m a n u+e d u}\right) \cdot\left(1-\frac{a g r+m a n u+e d u}{G D P M}\right)
\end{aligned}
$$

In which GDPM represents the environment utmost volume and if $l_{i}$ means education (technology) 
multiplier. And $\left(M_{l}+F_{l}\right) \cdot\left(\right.$ labor $\left._{3} \cdot M R_{E}\right)$ acts as human resource multiplier.

And for population growth, we specially have:

$$
d p o p=\sigma \cdot p o p \cdot\left(1-\frac{p o p}{a g r}\right) \cdot\left(1-\frac{a g r+m a n u+e d u}{G D P M}\right)-d e a t h
$$

In which $\sigma$ means the average birth rate, $1-\frac{p o p}{a g r}$ means the foods restriction to population growth and others' meaning are same to equations above.

Figure 4 shows our models outcome of decade growth of our Population Zero with suitable initial parameters. We can clearly observe from the figure that though agriculture and manufactory start at same point, agriculture grows slightly faster than manufactory. That is because manufactory relies more on advanced technology and at the very beginning Population Zero did not obtain high education and science level. And we can also see from the figure that the education grows slower than other two departments and has a rather stable growing speed.

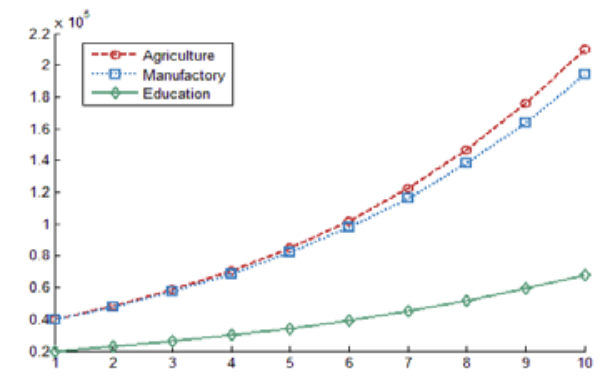

Figure 4: three departments' growth

Now, we take objective function into consideration. As we have stated above, we mainly have three goals: income, education and equality. We want our society has high annual income, high education level and less unfair among people. And in this question, we use the variance of citizen income to indicate the equality of this society. Thus, we set our objective function as below:

$$
W=\frac{(\text { agri }+ \text { manue }) \cdot e d u}{\operatorname{Stad}\left(\text { income }_{i}\right)}
$$

Therefore, we have set up anoptimization model, as is shown below:

$$
\max W=\frac{(\text { agri }+ \text { manue }) \cdot e d u}{\text { Stad }\left(\text { income }_{i}\right)}
$$

$$
\text { s.t.GDFM } \leq L
$$

In which $L$ means the restriction of Mars resource. And we found when labor $_{1}:$ labor $_{2}:$ labor $_{3}=0.31: 0.28: 0.41, \mathrm{~W}$ reaches its maximum.

\section{Model Evaluation}

\section{Strengths}

- Our model is very convenient in controlling parameters and observing outcomes. This would highly benefit researcher when applying Variable-controlling approach. 
- Our model has wide applicability and versatility, which would be helpful when circumstance changes.

\section{Weaknesses}

- Our model is abstracted on some aspects and did not take some detail into consideration, which make our model sometimes might perform Inaccuracy.

\section{Improvements}

- We could consider more departments in our model such as transportation, entertainment and etc. to make our model more like real world. Also, we could consider more kinds of people such as collage teacher, middle school teacher and researcher.

\section{Reference}

[1]Urdal. Henrik, A Clash of Generations? Youth Bulges and Political Violence. International Studies Quarterly, 50:607-29, 2006.

[2]Heather Randell , Clark Gray ,Climate variability and educational attainment: Evidence from rural Ethiopia,Global Environmental Change, Vol.41Elsevier, 2016. 